\title{
Early Experience with Diode Laser Combined with Systemic Steroid Therapy for Severe Stages of Retinopathy of Prematurity
}

Monika Modrzejewska ${ }^{1 *}$, Ewelina Lachowicz ${ }^{1}$, Joanna Kot $D^{1}$, Wojciech Lubiński ${ }^{1}$, Jacek Rudnicki², Beata Czeszyńska ${ }^{3}$, Anna Modrzejewska ${ }^{1}$ and Jacek Patalan ${ }^{4}$

${ }^{1}$ Department of Ophthalmology, Pomeranian Medical University, Powst, WIkp. Str. 72, 70111 Szczecin, Poland

${ }^{2}$ Department of Neonatal Pathology, Pomeranian Medical University, Powst, Wlkp. Str. 72, 70111 Szczecin, Poland

${ }^{3}$ Departament of Neonatology Pomeranian Medical University, Siedlecka Str. 2, Police, Poland

${ }^{4}$ Department of Neonatal Intensive Care Sp SZOZ-Zdroje, Mączna Str. 4, Szczecin, Poland

\begin{abstract}
Aims: To study the efficacy of diode laser-systemic steroid therapy in extremely and very-low-birth-weight prematures with severe Retinopathy of Prematurity (ROP).

Methods: 36 eyes of 18 prematures, mean gestational age 25.67 weeks (SD \pm 1.28 ) and $811,83 \mathrm{~g}$ birth weight (SD \pm 299.08 ) with aggressive-posterior ROP (AP-ROP) and threshold 3 ROP with plus sign and Extraretinal Fibrovascular Proliferation (EFP) were enrolled. Indirect diode laser combined with intravenous course of Dexamethason was applied. Analyzed risk factors were correlated with the same ones received in cohort treated only with laser. Shapiro-Wilk, t-Student, U Mann-Whitney tests were involved in the statistical analysis (significance levels at $p<0.05$ ).

Results: Favorable anatomical results after mean 11.29 (SD \pm 2.29 ) days of therapy were noted in 32 eyes $(88.88 \%)$, ROP 5 developed in four eyes, but this difference was statistically non-significant $(p=0.0612)$. Transient cortisol decreasing, hyperglycemia and partial adrenal fatigue were noted in some babies. During therapy, arterial systolic and diastolic pressures rose $(p<0.05 ; p<0.01)$, significantly, which were related with severity of ROP, such as, $C$-reactive protein, erythrocyte and hematocrit, ventilation duration and number of transfusion $(p<0.01)$.
\end{abstract}

Conclusion: Laser-steroid treatment might be additional effective alternative for severe ROP. Short- and long-term complications should be taken into account when starting this type of therapy.

Keywords: Retinopathy of prematurity; Systemic steroids application; Diode laser panfotocoagulation; Proinflammatory agents; Vasoproliferative factors

Abbreviations: ROP: Retinopathy of Prematurity; IL-6: Interleukin 6; CRP: C-Reactive Protein; IL-17: Interleukin 17; IL-8: Interleukin 8; TGF- $\alpha$ : Transforming Growth Factor- $\alpha$; BDNF: Brain Derived Neurotrophin Factor; NT4: Neurotrophin-4; PDGF: Platelet-Derived Growth Factor; IGF-I: Insulin-Like Growth Factor; EGF: Epidermal Growth Factor; FGF: Fibroblast Growth Factor I; HIF-1 a: Hypoxia Inducible Factor; PKC: Protein Kinase C; SIMV: Synchronized Intermittent Mandatory Ventilation; IMV: Intermittent Mandatory Ventilation; IPPV: Intermittent Positive Pressure Ventilation; nCPAP: nasal Continuous Positive Airway Pressure; HFOV: High Frequency Oscillatory Ventilation

\section{Introduction}

Retinopathy of prematurity (ROP) is a vasoproliferative disease of the developing retina, complications of which might be the major cause of vision deterioration and blindness in infancy. This pathology is a biphasic process consisting of an initial phase of blunted vascular growth followed by a second phase of vasoproliferation that may be recognized by ophthalmoscopy 6 to $8 \mathrm{wks}$ after birth [1]. Fundamental initiating process involved in retinal vascular development is angiogenesis which is regulated by growth factors, extracellular matrix components and complex of anti-and pro-inflammatory cytokines, among which IL-6, CRP, IL-17, IL-18, TNF $\alpha$, TGF- $\beta$, BDNF, NT4, PDGF, IGF-I, EGF, FGF, PKC - protein kinase C- and HIF-1 $\alpha$ are recognized as key factors in the development of ROP. They have ability to modulate angiogenesis in ROP and are involved in dysregulation of this pathological phenomenon mainly through up-regulating VEGF messenger RNA synthesis, in response to tissue hypoxia or inflammation [2-4]. Additionally, it has been revealed that the so-called Fetal Inflammatory Response (FIRS) is the result of chorioamnionitis, antenatal intrauterine as well as Candida infections which are important agents in pathogenesis of prematurity complications such as sepsis, Periventricular Leukomalacia (PVL), Intraventricular Hemorrhage (IVH), Necrotizing Enterocolitis (NEC) or bronchopulmonary dysplasia $[2,3,5,6]$. There are also studies which state that the abovementioned factors intensify frequency and severity of ROP, however neonatal noninfectious inflammation might further increase the inflammatory burden [5-7].

Dexamethasone is one of the mostly applied corticosteroids, both in different ophthalmological as well as in perinatal and neonatal disorders, where in the latter it is commonly used to limit the severity of chronic lung disease with severe respiratory distress syndrome [8]. It is the most potent anti-inflammatory agent, although the mode of its action has been poorly understood to this date. Some results of clinical and experimental studies have confirmed the decrease of the severity of retinopathy before and during oxygen exposure after intravenous administration of Dexamethasone in the mouse model and in broncho-pulmonary dysplasia [8-13]. Moreover, by modulating

*Corresponding author: Monika Modrzejewska MD PhD, Pomeranian Medical University, Powst. Wlkp. 72, 70111 Szczecin, Poland, Tel: +48914661296; E-mail: monika_modrzej@op.pl

Received July 26, 2014; Accepted October 31, 2014; Published November 04, 2014

Citation: Modrzejewska M, Lachowicz E, Joanna Kot D, Lubiński W, Rudnicki J, et al. (2014) Early Experience with Diode Laser Combined with Systemic Steroid Therapy for Severe Stages of Retinopathy of Prematurity. J Steroids Horm Sci 5: 148. doi: $10.4172 / 2157-7536.1000148$

Copyright: (c) 2014 Modrzejewska M, et al. This is an open-access article distributed under the terms of the Creative Commons Attribution License, which permits unrestricted use, distribution, and reproduction in any medium, provided the original author and source are credited. 
Citation: Modrzejewska M, Lachowicz E, Joanna Kot D, Lubiński W, Rudnicki J, et al. (2014) Early Experience with Diode Laser Combined with Systemic Steroid Therapy for Severe Stages of Retinopathy of Prematurity. J Steroids Horm Sci 5: 148. doi:10.4172/2157-7536.1000148

Page 2 of 7

TNF- $\alpha$, it simultaneously changes expression of the mentioned factor, which is important in reduction of inflammation and angiogenesis processes [14]. The purpose of this study was to present the preliminary outcomes for application of diode laser panfotocoagulation supported by systemic intravenous Dexamethasone course for selected severe stages of retinopathy of prematurity.

\section{Subjects and Methods}

A retrospective, comparative study was performed. Screening ophthalmic examinations were performed in 657 prematurely born babies. The examined subjects were under systematic, periodical supervision of Ophthalmic and Neonatal Clinical Departments and the follow-up period in this group was 3-years. Among that group, diode laser panfotocoagulation was undertaken in 48 infants (7.30\%), however laser-steroid therapy was performed in 18 (2.73\%) out of this treated group as a result of severe stages of ROP and rapid progression of the disease. Information on the course of ROP and the therapeutic management during the ophthalmologic care was collected from the medical records, computer images and what should be underlined, ophthalmic examinations were performed by one and the same experienced ophthalmologist and included: the funduscopy visualized by Ret-Cam II method (Clarity Medical Systems), ultrasonography (US3300 Echo-Scan ultrasonic B-scan with $10-\mathrm{MHz}$ sector probe equipment -Nidek Co. Japan) and intraocular pressure assessed by I-care PRO
Tonometer (Icare Finland Oy). Diode laser panfotocoagulation (Iris Medical, Ocu- Light S) of peripheral avascular retina was undertaken in general inhalatory anesthesia, with the mean parameters: power 200 $500 \mathrm{~mW}$, application time $50 \mathrm{~ms}$, number of foci for one eye about 2454 \pm 1525 . Schedule of follow-up ophthalmic examinations was conducted individually for each baby, every 5-7 days in first weeks of observation until regression of the retinal lesions connected with the disease, next every 7-14 days in the first two months of post-operational period and subsequently it was prolonged to every 3-4 weeks for next two months. Prior to inclusion of laser-steroids therapy, prematures' parents had acknowledged the details of the disease course and the possibilities of its treatment on present day. They had also been informed about the option of Dexamethasone management as nonstandard therapy in ROP, taking into account mostly benefits but also likelihood of complications connected with steroids known from its use in various ophthalmic and multiorgan pathologies. Special emphasis was put on the side effects connected with steroids therapy, about which the parents were informed in much detail. After the written consent, systemic steroids course started being included. The study was approved by local ethics committee (approval No. KB-0012/52/12/10).

\section{Data Collection}

Detailed demographic, intrapartum, gestational, neonatal data were collected from patients' medical charts. Analyzed parameters were

\begin{tabular}{|c|c|c|c|c|c|c|c|c|}
\hline Case \# & Sex & Gestational age (weeks) & Birth Weight (g) & Delivery type & Causes for preterm birth & Pregnancy & Pregnancy/Delivery & Apgar score \\
\hline 1 & $\mathrm{~F}$ & 25 & 650 & $\mathrm{~N}$ & $\begin{array}{l}\text { preterm amniorrhexis, } \\
\text { intrauterine infection }\end{array}$ & $\mathrm{s}$ & $\begin{array}{l}\text { PIII } \\
\text { DIII }\end{array}$ & $2,3,4$ \\
\hline 2 & M & 27 & 1105 & C & $\begin{array}{l}\text { preterm amniorrhexis, } \\
\text { intrauterine infection }\end{array}$ & $\mathrm{s}$ & $\begin{array}{l}\text { PIII } \\
\text { DII }\end{array}$ & $1,1,1$ \\
\hline 3 & $\mathrm{~F}$ & 24 & 600 & C & Intrauterine infection & $\mathrm{s}$ & $\begin{array}{l}\text { PV } \\
\text { DII }\end{array}$ & $4,4,5$ \\
\hline 4 & M & 28 & 1750 & C & Intrauterine infection & $s$ & $\begin{array}{l}\text { PIII } \\
\text { DII }\end{array}$ & $6,4,7$ \\
\hline 5 & $\mathrm{~F}$ & 25 & 530 & $\mathrm{~N}$ & $\begin{array}{l}\text { preterm amniorrhexis, } \\
\text { intrauterine infection }\end{array}$ & $\mathrm{s}$ & $\begin{array}{l}\mathrm{Pl} \\
\mathrm{DI}\end{array}$ & $2,2,3$ \\
\hline 6 & $\mathrm{~F}$ & 25 & 530 & C & $\begin{array}{c}\text { placental abruption, threatening } \\
\text { haemorrhage }\end{array}$ & $s$ & $\begin{array}{l}\text { PV } \\
\text { DIII }\end{array}$ & $0,6,6$ \\
\hline 7 & M & 25 & 850 & C & placental abruption & M (2) & $\begin{array}{l}\text { PIII } \\
\text { DIII }\end{array}$ & $4,7,8$ \\
\hline 8 & M & 24 & 700 & C & $\begin{array}{l}\text { hernia of foetal membranes, } \\
\text { cross-birth, intrauterine infection }\end{array}$ & $\mathrm{s}$ & $\begin{array}{l}\text { PIV } \\
\text { DII }\end{array}$ & $1,1,1$ \\
\hline 9 & M & 28 & 1200 & C & preterm amniorrhexis. & M (2) & $\begin{array}{l}\text { PII } \\
\text { DII }\end{array}$ & $6,6,7$ \\
\hline 10 & $\mathrm{~F}$ & 27 & 900 & C & $\begin{array}{c}\text { placental abruption, intrauterine } \\
\text { infection }\end{array}$ & $\mathrm{s}$ & $\begin{array}{l}\text { PIII } \\
\text { DIII }\end{array}$ & $5,5,6$ \\
\hline 11 & $\mathrm{~F}$ & 25 & 600 & N & $\begin{array}{c}\text { placental abruption, intrauterine } \\
\text { infection }\end{array}$ & $\mathrm{s}$ & $\begin{array}{l}\mathrm{PI} \\
\mathrm{DI}\end{array}$ & $2,2,2$ \\
\hline 12 & $\mathrm{~F}$ & 25 & 720 & C & placental abruption & M (2) & $\begin{array}{l}\text { PIII } \\
\text { DIII }\end{array}$ & $5,5,8$ \\
\hline 13 & M & 26 & 650 & C & $\begin{array}{l}\text { preterm amniorrhexis, } \\
\text { intrauterine infection }\end{array}$ & $\mathrm{s}$ & $\begin{array}{l}\mathrm{PI} \\
\mathrm{DI}\end{array}$ & $2,2,2$ \\
\hline 14 & M & 26 & 760 & c & preterm amniorrhexis & $\mathrm{s}$ & $\begin{array}{l}\text { PIV } \\
\text { DIII }\end{array}$ & $5,6,6$ \\
\hline 15 & M & 24 & 560 & $\mathrm{~N}$ & preterm amniorrhexis & $S$ & $\begin{array}{l}\text { PV } \\
\text { DV }\end{array}$ & $6,6,6$ \\
\hline 16 & M & 27 & 790 & c & intauterine infection & $\mathrm{s}$ & $\begin{array}{c}\text { PIII } \\
\text { DI }\end{array}$ & $4,4,7$ \\
\hline 17 & $\mathrm{~F}$ & 26 & 830 & N & intrauterine infection & $\mathrm{s}$ & $\begin{array}{l}\text { PIII } \\
\text { DII }\end{array}$ & $5,5,6$ \\
\hline 18 & M & 25 & 888 & $\mathrm{~N}$ & intrauterine infection & $S$ & $\begin{array}{l}\mathrm{PI} \\
\mathrm{DI}\end{array}$ & $5,6,6$ \\
\hline
\end{tabular}

Table 1: Characteristics of demographic, intrapartum, gestational and neonatological factors in studied group of premature babies.

Case \#- patient's number, Sex: M- male, F- female, Delivery type: N- natural delivery, C-cesarean section, Pregnancy: S- single pregnancy, M- multiple pregnancy, P-pregnancy, D-delivery, SD- standard deviation. 
Citation: Modrzejewska M, Lachowicz E, Joanna Kot D, Lubiński W, Rudnicki J, et al. (2014) Early Experience with Diode Laser Combined with Systemic Steroid Therapy for Severe Stages of Retinopathy of Prematurity. J Steroids Horm Sci 5: 148. doi:10.4172/2157-7536.1000148

Page 3 of 7

showed in Table 1. Prior to inclusion of diode laser-steroid treatment, diagnosis of advanced stages of ROP had been done on the basis of ophthalmic RET-Cam II visualization and according to International Classification of Retinopathy of Prematurity (ICROP) criteria [15]. Eighteen extremely and very low birth weight prematures (ELBW and VLBW) born to multiparas $(\mathrm{n}=13 ; 72.22 \%)$ and primiparas $(\mathrm{n}=5$; $27.77 \%)$, singleton pregnancy ( 15 neonates) and multiple pregnancy $(3$ newborns) among which 8 females and 10 males were enrolled. The average age was 25.67 weeks $(\mathrm{SD} \pm 1.28)$ and mean birth weight was 811.83g ( $\mathrm{SD} \pm 299.08$ ). For comparison, a control group comprised of eighteen volunteer-babies treated for ROP with diode laser panfotocoagulation only ( 9 females and 9 males) whose mean weight, age- and sex distributions were similar to those from the study group (Table 5).

\section{Diode Laser Treatment,SystemicSteroid Administration and Local Treatment}

\section{Inclusion criteria}

Among pediatric patients, the reason for general steroids therapy (Dexamethason sodium phosphate, Krka d.d., Novo mesto) inclusion was the presence of severe and rapidly progressing stages of threshold ROP: both ROP 3B and plus sign with Extraretinal Fibrovascular Proliferation (EFP) as well as agressive-posterior ROP (AP-ROP) which were confirmed in $6(33.34 \%)$ and $12(66.66 \%)$ prematures, respectively (Table 2). The abovementioned lesions were accompanied in some cases by pre-retinal hemorrhages located just in front of and on the ridge or extending in posterior pole of retina and posterior vitreous. Intravenous corticosteroids were used within 65.05 ( $\mathrm{SD} \pm 1.25$ ) days of life; that is 34.69 ( $\mathrm{SD} \pm 1.06)$ postmenstrual week, Table 2. It was being administered twice a day to eighteen babies for the period of 9-16 days,
11.29 ( $\mathrm{SD} \pm 2.29$ ) on average. The starting dose was $0.3 \mathrm{mg} / \mathrm{kg} /$ day for consecutive 3 days and then gradually decreasing by half every 3 days until reaching $0.08 \mathrm{mg} / \mathrm{kg} /$ day as a final dose. In the basic schedule, 9 days of the therapy was suggested. Prolonging the drug application that is 12 days in nine babies and 16 days in three newborns was caused by aggressive course of the retinopathy coexisting with diseases of inflammatory origin. In case of no intravenous access, final drug dose was applied orally in two newborns. Duble blind trial was not used due to the knowledge about steroids action and their beneficial application in ophthalmic diseases of inflammatory origin both in adults as well as in children. Presuming the adverse effects of steroids, the mean values of the following parameters were evaluated: systolic and diastolic arterial blood pressures, blood glucose levels, tyreotropin, C-reactive protein, total bilirubin, as well as hematocrit, hemoglobin and erythrocyte titers (Table 3). In local treatment, Dexamethasone $0.1 \%$, and Diclofenac in eye drops was used. Additionally, antihemorrhagic, absorbent, anti-permeability and anti-inflammatory drugs were included at the presence of multi-organ complications coexisting with subretinal hemorrhages. All infants from the analyzed group received single dose of surfactant because of Respiratory Distress Syndrome (RDS). Moreover, inhalatory steroids treatment was applied in 7 infants (38.88\%) due to bronchopulmonary dysplasia (BPD), Table 3.

\section{Exclusion criteria}

Confirmation of viral infections in laboratory tests might be the exclusion criteria for the combined therapy, however it has not been noticed in the studied group.

\section{Statistical tests}

The normality of the distribution of individual traits was analyzed with the Shapiro-Wilk test. The differences in parameters between

\begin{tabular}{|c|c|c|c|c|c|c|c|c|}
\hline Case \# & $\begin{array}{c}\text { ROP } \\
\text { right eye }\end{array}$ & $\begin{array}{c}\text { ROP } \\
\text { left eye }\end{array}$ & $\begin{array}{l}\text { Postmenstrual } \\
\text { age when } \\
\text { course started }\end{array}$ & $\begin{array}{c}\text { Duration of } \\
\text { therapy (days) }\end{array}$ & Therapy effect & $\begin{array}{c}\text { Cortisol-1 } \\
\mathrm{ng} / \mathrm{ml}\end{array}$ & $\begin{array}{c}\text { Cortisol- } 2 \\
\mathrm{ng} / \mathrm{ml}\end{array}$ & $\begin{array}{c}\text { Cortisol -3 } \\
\mathrm{ng} / \mathrm{ml}\end{array}$ \\
\hline 1 & AP & AP & 36 & 12 & $\mathrm{Y}$ & 0 & 0 & 0 \\
\hline 2 & $\begin{array}{l}3 \mathrm{~B}+ \\
\text { EFP }\end{array}$ & $\begin{array}{l}3 \mathrm{~B}+ \\
\text { EFP }\end{array}$ & 35 & 9 & $\mathrm{Y}$ & 13.17 & 1.89 & 50.87 \\
\hline 3 & AP & AP & 34 & 16 & $Y$ & 26.04 & 3.08 & 56.11 \\
\hline 4 & $\begin{array}{l}3 \mathrm{~B}+ \\
\text { EFP }\end{array}$ & $\begin{array}{l}3 B+ \\
\text { EFP }\end{array}$ & 34 & 9 & $\mathrm{Y}$ & 0 & 0 & 0 \\
\hline 5 & AP & AP & 34 & 12 & $Y$ & 0 & 0 & 0 \\
\hline 6 & AP & AP & 33 & 16 & $Y$ & 19.6 & 6.78 & 59.22 \\
\hline 7 & $\begin{array}{l}3 B+ \\
\text { EFP }\end{array}$ & $\begin{array}{l}3 B+ \\
\text { EFP }\end{array}$ & 35 & 12 & $Y$ & 0 & 0 & 0 \\
\hline 8 & AP & AP & 36 & 14 & $Y$ & 18.55 & 7.65 & 78.98 \\
\hline 9 & $3 \mathrm{~B} / 4 \mathrm{~A}+$ & $\begin{array}{l}3 B+ \\
\text { EFP }\end{array}$ & 34 & 12 & $\mathrm{Y}$ & 0 & 0 & 0 \\
\hline 10 & 3B+EFP & $\begin{array}{l}3 \mathrm{~B}+ \\
\text { EFP }\end{array}$ & 35 & 9 & $Y$ & 0 & 0 & 0 \\
\hline 11 & $3 B+E F P$ & $\begin{array}{l}3 \mathrm{~B}+ \\
\text { EFP }\end{array}$ & 34 & 9 & $\mathrm{Y}$ & 0 & 0 & 0 \\
\hline 12 & AP & $A P$ & 35 & 12 & $\mathrm{Y}$ & 0 & 0 & 0 \\
\hline 13 & AP & AP & 34 & 12 & $\mathrm{Y}$ & 27.88 & 5.47 & 66.68 \\
\hline 14 & AP & AP & 36 & 9 & $\mathrm{~N}$ & 24.78 & 4.06 & 75.34 \\
\hline 15 & AP & AP & 35 & 12 & $Y$ & 0 & 0 & 0 \\
\hline 16 & AP & AP & 35 & 9 & $\mathrm{~N}$ & 0 & 0 & 0 \\
\hline 17 & AP & AP & 34 & 12 & $\mathrm{Y}$ & 28.64 & 5.40 & 69.88 \\
\hline 18 & AP & AP & 34 & 12 & $\mathrm{Y}$ & 0 & 0 & 0 \\
\hline
\end{tabular}

Table 2: Data of the applied therapy and the advanced stage of ROP in consecutively studied prematures in whom combined therapy was applied

Case \# - consecutive patients number, ROP-retinopathy of prematurity, AP-aggressive-posterior ROP, EFP-extraretinal fibrovascular proliferation; ROP3B+ EFP - ROP 3B and ridge, fibrous component in EFP and Plus Disease, therapy effect: $\mathrm{Y}$-confirmed beneficial effect of treatment, N-No beneficial effect of treatment, Cortisol-1-Cortisol titer in 1-st day of course, Cortisol-2-Cortisol titer after 14 days of completed therapy, Cortisol-3-Cortisol titer after 3 months of completed therapy, (0- no measure). 
Citation: Modrzejewska M, Lachowicz E, Joanna Kot D, Lubiński W, Rudnicki J, et al. (2014) Early Experience with Diode Laser Combined with Systemic Steroid Therapy for Severe Stages of Retinopathy of Prematurity. J Steroids Horm Sci 5: 148. doi:10.4172/2157-7536.1000148

Page 4 of 7

\begin{tabular}{|c|c|c|c|c|c|c|c|c|}
\hline Case \# & SBP/DBP $\mathrm{mmHg}$ & $\underset{\mathrm{mmol} / \mathrm{I}}{\mathrm{GL}}$ & $\begin{array}{l}\text { TSH } \\
\mathrm{IU} / \mathrm{mL}\end{array}$ & $\begin{array}{l}\mathrm{CRP} \\
\mathrm{mg} / \mathrm{l}\end{array}$ & $\begin{array}{c}\text { Total BIL } \\
\mathrm{mg} / \mathrm{dl}\end{array}$ & $\begin{array}{l}\mathrm{Ht} \\
\%\end{array}$ & $\begin{array}{l}\mathrm{Hb} \\
\mathrm{g} / \mathrm{dl}\end{array}$ & $\begin{array}{c}E \\
T / L\end{array}$ \\
\hline 1 & $75 / 54$ & 3.66 & 2.56 & 24.32 & 6.16 & 25.4 & 8.40 & 2.65 \\
\hline 2 & $77 / 46$ & 5.22 & 3.75 & 2.36 & 9.05 & 29.6 & 10.50 & 3.50 \\
\hline 3 & $70 / 56$ & 5.49 & 0.847 & 3.15 & 7.54 & 28.68 & 10.54 & 3.40 \\
\hline 4 & $75 / 55$ & 5.55 & 0.67 & 4.89 & 9.76 & 26.97 & 9.69 & 2.97 \\
\hline 5 & $82 / 54$ & 5.49 & 3.74 & 92.02 & 11.79 & 22.38 & 7.70 & 2.45 \\
\hline 6 & $80 / 67$ & 6.60 & 3.87 & 17.43 & 9.54 & 28.44 & 6.50 & 2.47 \\
\hline 7 & $76 / 47$ & 6.22 & 4.80 & 10,79 & 5.13 & 25.11 & 7.70 & 2.93 \\
\hline 8 & $79 / 52$ & 5.44 & 2.56 & 11.98 & 6.71 & 27.01 & 6.98 & 2.77 \\
\hline 9 & $70 / 55$ & 7.55 & 6,15 & 34.89 & 4.9 & 30.50 & 10.6 & 3.59 \\
\hline 10 & $81 / 54$ & 6.55 & 5.54 & 2.78 & 7.7 & 28.54 & 9.54 & 3.21 \\
\hline 11 & $78 / 60$ & 5.16 & 3.44 & 27.50 & 6.96 & 29.41 & 10.42 & 2.83 \\
\hline 12 & $78 / 59$ & 6.16 & 4.44 & 4.37 & 7.05 & 24.10 & 8.99 & 2.83 \\
\hline 13 & $80 / 63$ & 5.11 & 3.12 & 9.08 & 6.98 & 27.01 & 7.75 & 2.76 \\
\hline 14 & $77 / 50$ & 4.33 & 0.41 & 29.88 & 23.98 & 32.00 & 7.91 & 3.55 \\
\hline 15 & $79 / 40$ & 4.99 & 0.77 & 8.56 & 5.36 & 23.01 & 9.42 & 2.76 \\
\hline 16 & $70 / 59$ & 6.38 & 9,14 & 42.98 & 4.89 & 23.33 & 8.37 & 2.84 \\
\hline 17 & $77 / 45$ & 5.72 & 0.86 & 69.54 & 7.65 & 24.01 & 9.65 & 2.44 \\
\hline 18 & $74 / 50$ & 5.38 & 3.18 & 77.09 & 5.34 & 24.77 & 8.20 & 2.52 \\
\hline
\end{tabular}

Table 3: Mean values of selected laboratory factors in consecutively studied pre-matures with severe ROP in whom combined therapy was applied.

Case \#- consecutive patient's number, APs- systolic arterial pressure, APd- diastolic arterial pressure, GL-mean glucose (normal babies' level 2.78-4.44mmol), TSH-mean tyreotropin (normal values from 2 weeks of life to 2 years old 0.8-9.1 IU/ml), CRP-mean C-reactive protein (normal 0-5mg/l), Total BIL-total bilirubin (normal<5.0 mg/dl), Ht-mean hematocrit (Normal 34-41\%), Hb-mean hemoglobin, Er-mean erythrocyte (normal 4.3-5.5 mln/ul)

\begin{tabular}{|c|c|c|c|c|c|c|c|c|c|c|}
\hline Case \# & RDS & BPD & IVH & Hydrocephalus & Transfusion No. & Ventilation/days & Pneumonia & NEC & Osteopenia & PDA \\
\hline 1 & III & + & III & + & 3 & 56 & + & + & 0 & 0 \\
\hline 2 & II & 0 & III & 0 & 6 & 33 & + & 0 & 0 & + \\
\hline 3 & IV & + & III & + & 7 & 57 & + & 0 & + & + \\
\hline 4 & II & 0 & II & 0 & 5 & 13 & 0 & 0 & 0 & 0 \\
\hline 5 & IV & + & III & + & 15 & 64 & + & + & 0 & + \\
\hline 6 & $\mathrm{I} / \mathrm{II}$ & 0 & II & 0 & 14 & 52 & + & + & 0 & + \\
\hline 7 & IV & + & III & + & 11 & 64 & + & + & 0 & + \\
\hline 8 & III & 0 & II & 0 & 8 & 40 & 0 & 0 & 0 & 0 \\
\hline 9 & II & 0 & II & 0 & 5 & 25 & + & 0 & 0 & 0 \\
\hline 10 & 1 & 0 & III & 0 & 4 & 16 & + & 0 & 0 & + \\
\hline 11 & II & 0 & III & + & 6 & 50 & + & 0 & + & + \\
\hline 12 & IV & 0 & III & + & 13 & 50 & + & + & 0 & + \\
\hline 13 & II & 0 & III & 0 & 7 & 44 & 0 & + & 0 & + \\
\hline 14 & II & + & IV & 0 & 5 & 12 & 0 & 0 & 0 & 0 \\
\hline 15 & 1 & 0 & III & + & 13 & 40 & 0 & 0 & 0 & + \\
\hline 16 & III & + & IV & + & 9 & 60 & + & + & + & + \\
\hline 17 & II & 0 & II & + & 3 & 65 & + & + & 0 & 0 \\
\hline 18 & II & + & III & & 2 & 56 & + & + & + & + \\
\hline
\end{tabular}

Table 4: Characteristics of clinical features in consecutively studied prematures with severe ROP in whom combined therapy was applied.

Case \# - consecutive patients number, RDS-respiratory distress syndrome (I,II,III,IV RDS-stages of RDS), BPD-bronchopulmonary dysplasia, (+/0 - presence or absence of examined feature), IVH-intraventricular hemorrhage, Transfusion No.-number of transfusions, Ventilation-mechanical ventilation (number of days), NEC-enterocolitis necroticans, PDA-patent ductus arteriosus, L-DPA patent ductus arteriosus surgical ligation.

groups were determined with the t-Student test, whereas the MannWhitney $U$ test was used in the case of deviations from the normal distribution. The differences describing the number of retina attachments in the laser steroid group and the controls were measured with accurate Fisher test. Value probability was put in the table from the results of each test. Statistical significance of the parameters and the differences between them were tested at the significance levels of $p<0.01$ and $\mathrm{p} p<0.05$.

\section{Results}

Premature spontaneous delivery was confirmed in 6 babies (33.33\%), caesarian section was noted in 12 newborns (66.66\%). The risk factors in a course of pregnancy for premature childbirth were as follows: preterm amniorrhexis, intrauterine infection, premature placental abruption with threatening hemorrhages and hernia of membranes and cross-birth (Table 1). The abovementioned values were not statistically different in relation to the controls. Retina attachment was observed in 16 newborns (32 eyes; 88.88\%) and varied in comparison to diode-laser alone preterms (12 eyes; 33.33\%). However, this beneficial effect was not statistically significant $(p=0.0612)$. In 2 babies (4 eyes; $11.11 \%$ ) intravenous steroid application was interrupted after 9 days due to partial adrenal fatigue of iatrogenic origin. In them retina detachment was noticed (Table 2). Unfortunately, cortisol titer was evaluated only in some patients $(n=7)$ because there was no constant scheme of its assessment on different neonatology units where the babies were hospitalized. In this group of patients, in the 
day of starting and ending the treatment, cortisol morning titers were $22.66 \mathrm{ng} / \mathrm{ml}(\mathrm{SD} \pm 5.07)$ and $4.90 \mathrm{ng} / \mathrm{ml}(\mathrm{SD} \pm 2.03)$ on average, respectively. Three months after the course completion, cortisol level increased to $65.29 \mathrm{ng} / \mathrm{ml}$ ( $\mathrm{SD} \pm 10.33$ ), Table 2 . The averaged outcomes of laboratory tests turned out to be statistically insignificant and included: tyreotropin, bilirubin, glucose and hemoglobin levels (Table 3). Additionally, the incidence of following coexisting diseases was confirmed: bronchopulmonary dysplasia, osteopenia, intraventricular hemorrhage and hydrocephalus, pneumonia, enterocolitis necroticans, patent ductus arteriosus with its surgical closure, Table 4. Moreover, leucopenia, leukocytosis, thrombocytopenia, electrolyte dysregulation, metabolic acidosis, hypofibrinogenemia and parenteral alimentation were confirmed being without statistical significance in comparison to control group. The noticed increase of CRP (mean $37.39 \mathrm{mg} / \mathrm{l}$ ) turned out to be statistically relevant $(p=0.0000)$ (Table 5). Elevation of this factor was also significantly related to progression of ROP, being the highest in AP-ROP $(r=0.5515)$ v.s. 3 ROP $(r=0.3986 ; \mathrm{p}<0.01)$. Decreased $\mathrm{Ht} 26.68 \%(\mathrm{SD} \pm 2.88)$ and $\operatorname{Er} 2.95 \mathrm{~T} / \mathrm{L}(\mathrm{SD} \pm 0.38)$, were statistically relevant $(\mathrm{p}<0.01)$, and together with lowering $\mathrm{Hb} 7.82 \mathrm{~g} / \mathrm{l}(\mathrm{SD} \pm 1.27)$ were the reason for multiple transfusions of packed red blood cells (PRBCs) in all studied babies $(\mathrm{n}=18)$, average 9.75 ( $\mathrm{SD} \pm 3.34)$, (Tables 3 and 5). Association between high number of transfusion remained statistically significant $(p=0.0000)$. This amount was significantly connected with progression of ROP, being the highest in AP-ROP v.s.3 ROP ( $r=0.5053 ; r=0.4010)$. Mechanical ventilation: SIMV, IMV, IPPV and nCPAP were applied in all babies; however additional HFOV was used in 2 of them, in whom retina detachment was observed in followup period. Duration of ventilation was 57.83 days, average ( $\mathrm{SD} \pm 15.89$ ) and was significantly higher in laser-steroid patients $(\mathrm{p}=0.0000)$. It was prolonged in severe stages of ROP $(r=0.5579$ in AP-ROP and $r=0.3908$ in 3ROP).

\section{Discussion}

Retinopathy of prematurity (ROP) develops mostly in very low- and in extremely-low birth weight babies (VLBW and ELBW).

\begin{tabular}{|c|c|c|c|c|c|}
\hline \multirow{2}{*}{ Examined factors } & \multicolumn{2}{|c|}{ ROP $(\mathbf{n}=\mathbf{1 8})$} & \multicolumn{2}{|c|}{ Controls $(\mathbf{n + 1 8})$} & \multirow{2}{*}{$\mathbf{p}$} \\
\cline { 2 - 5 } & Mean & $\mathbf{s d}$ & Mean & $\mathbf{s d}$ & \\
\hline GA & 25.66 & 1.21 & 25.83 & 1.72 & 0.7344 \\
\hline BW & 811.83 & 156.9 & 819.44 & 134.39 & 0.8764 \\
\hline GL & 5.61 & 0.84 & 5.07 & 1.00 & 0.0899 \\
\hline SBP & 76.38 & 3.96 & 80.94 & 7.73 & 0.0330 \\
\hline DBP & 53.67 & 6.61 & 58.50 & 1.36 & 0.0046 \\
\hline TSH & 3.32 & 0.60 & 3.35 & 1.01 & 0.9429 \\
\hline CRP & 37.39 & 5.69 & 0.86 & 0.98 & 0.0000 \\
\hline Total BIL & 7.47 & 2.86 & 6.67 & 2.30 & 0.3616 \\
\hline Ht & 26.68 & 2.88 & 33.70 & 2.87 & 0.0000 \\
\hline Hb & 7.82 & 1.27 & 8.43 & 1.73 & 0.2451 \\
\hline Er & 2.95 & 0.38 & 3.89 & 0.42 & 0.0000 \\
\hline Transfusion No. & 9.75 & 3.34 & 1.33 & 0.50 & 0.0000 \\
\hline Ventilation/days & 57.83 & 15.89 & 8.67 & 6.44 & 0.0000 \\
\hline
\end{tabular}

Table 5: Characteristics of the mean value of examined factors in newborns with retinopathy of prematurity treated with diode-laser and steroids in comparison to only laser-diode group.

ROP - Examined Group of Pre-matures with ROP3B+ EFP (Ridge, Fibrous Component in EFP and Plus Disease) and AP-ROP, Controls - Only Laser-treated Premature Group, sd-Standard Deviation, GA - Gestational Age, BW - Birth Weight, GL- Glucose, SBP - Systolic Arterial Pressure, DBP - Diastolic Arteria Pressure, TSH - Tyreotropin, CRP - C-Reactive Protein, Total BIL - Total Bilirubin, $\mathrm{Ht}$ - Hematocrit, $\mathrm{Hb}$ - Hemoglobin, Er - Erythrocyte, Transfusion No.-Number of Transfusions, Ventilation - Mechanical Ventilation Duration (Number of Days), p- significance level.
Apart from diode laser panfotocoagulation, cryotherapy and trials of antiangiogenic therapy, there is no knowledge so far about efficient and new methods of treatment for both aggressive posterior ROP (AP$\mathrm{ROP}$ ) as well as rapidly appearing, severe stages of threshold ROP with plus disease and EFP [16-18].

After familiarizing with the action mechanisms of corticosteroids as potent anti-inflammatory drugs as well as their therapeutic possibilities in treatment and preventing the premature complications such as Chronic Lung Disease (CLD), the authors of this study have tried to apply systemic steroid combined with typical diode laser use in cases of suddenly progressing severe ROP $[12-14,19,20]$. According to the schemes of postnatal steroid treatment of premature CLD in the selected group of ELBW and VLBW newborns with ROP, Dexamethasone has been implemented intravenously [8]. During Dexamethasone treatment, hypothyreosis was observed only in 3 babies (16.66\%). Moreover, cortisol titer remained in the lower range of laboratory norm already before the starting therapy, decreasing significantly on about 14th day of the course and returning to normal level on third month after the completed therapy. In accordance with other authors, levels of these hormones remain low in early postnatal period especially in VLBW and ELBW prematures which is connected with multi-organ immaturity simultaneously with the lack of the other adverse effects of iatrogenic drug application [19,21-28]. Moreover, important is that the newborns who develop BPD have low cortisol levels following ACTH stimulation during the first week of life, therefore the use of steroids in early postnatal period in case of BPD, seems to be justified $[19,26,27,29,30]$. The steroid therapy amounted to 11.29 days on average, which proved the procedure to be in compliance with steroids administered by other authors for BPD treatment. They applied the same or approximate dose of the drug, the administration of which started much earlier that is even below 8 day of life with continuation of the course even until 21-28 following days [8]. It should be noted on the basis of 3-year follow-up that the general condition of the analyzed newborns, did not show the presence of significant short and long distance cardiologic, gastrointestinal and neurologic complications, which could have been induced by steroids. However, it can not be excluded that clinical symptoms of significant transient rise of arterial pressures might be connected with implied steroids. Transient partial adrenal fatigue in the form of lack of appetite, weight loss, apathy and weakness on approximately 14-th day of the therapy were observed in two prematures. This was the reason for steroids termination. Such state might probably be related with coexistence of severe developmental immaturity, intrauterine growth retardation, congenital intestinal obstruction treated surgically, and metabolic bone disease. It could be hypothesized that the HFOV (High-Frequency Oscillatory Ventilation) used in those two most severe babies, through oscillating movement, might also have indirect influence on progressing retina deterioration in further step until its detachment, similarly to intraventricular haemorrhage which has been described in the literature [31].

Transient, nonsignificant increase of glycemia observed in laser -treated ROP prematures both with and without steroid course could possibly be the result of parenteral alimentation. Moreover, outcomes of neurological examination including 3-year follow-up period, did not confirm any additional features of any abnormalities in neurosensory development in connection to the application of the discussed drug. Nevertheless, the observed psychomotor retardation in most of the babies might be connected with general immaturity, intracranial hemorrhages' or the resulting hydrocephalus diagnosed in the first period of life [32]. The mentioned cranial lesions probably influenced eye movement disturbances such as nystagmus and squint 
Citation: Modrzejewska M, Lachowicz E, Joanna Kot D, Lubiński W, Rudnicki J, et al. (2014) Early Experience with Diode Laser Combined with Systemic Steroid Therapy for Severe Stages of Retinopathy of Prematurity. J Steroids Horm Sci 5: 148. doi:10.4172/2157-7536.1000148

Page 6 of 7

$[21,32]$. Most recent reports point out the presence of normal cerebral development in only $23.5 \%$ of VLBW newborns, confirming global, mental and psychomotor retardation in the remaining group with the lack of systemic steroids application [17]. Contrary to that, other data in the literature also underline that the majority of prematures exposed to Dexamethasone in BPD do not develop cerebral palsy or global developmental disability, nevertheless one cannot exclude other more subtle adverse effects after steroids in further periods of childhood $[1,8,29,30,33-35]$.

In experimental studies, it has been revealed that the prolonged exposure to Dexamethasone in the neonatal rats leads to alterations in behavior, corticosteron response to stress and changes in LimbicHypothalamic Pituitary Adrenal (LHPA) axis circuitry, nevertheless it is not known if similar dysregulatory changes in this system appear in the human [29]. It might not be precluded that post-steroids complications could be associated with sulfite preservatives contained in the drug [36]. Relating to the data from available literature, it is worth mentioning that there are no clinical observations in connection to steroids application due to retinopathy of prematurity, although their use is commonly known in different retinal or retino-vitreous diseases even in early childhood, so it appears to be impossible to rely on an opinion of other authors in this field [37-44]. Three-year follow-up of combined laser-steroid course indicate beneficial effect of such therapy in the form of retina attachment which has been confirmed in $88.8 \%$ selected cases. Validity of Dexamethasone use in advanced and severe ROP seems to be confirmed by hypothesis including the presence of proinflammatory agents in the development of retinal abnormalities. It is proved by the increased level of CRP in the analyzed laser-steroids group $(\mathrm{p}<0.01)$, being the highest in the most advanced ROP stages, coexisting with intrauterine infection, enterocolitis necroticans and pneumonia [2-5,7]. Moreover, in this group the significant increase of transfusion number, prolonged duration of ventilation and anemia was noticed ( $\mathrm{p}<0.01)$, which is in accordance with data in the literature [45].

The inflammatory hypothesis has been acknowledged by most recent reviews in literature in extensive meta-analysis (35 studies and 4971 participants) among others, in which application of steroids in BPD led to significant decreasing of inflammatory process as well as lowering incidence of severe ROP $[8,30]$. The explanation of this phenomenon might be the TNF- $\alpha$ expression regulation secreted as a response to hyperoxia and hypoxia, which is an important factor in inflammation and angiogenesis in the mouse model of oxygen-induced retinopathy [45]. Some authors present a lot of evidence that Dexamethasone provides a protective action mechanism against the development of severe retinopathy and extraretinal neovascularization $[8,11,14,30,41]$. There exists a similarity to inhibitory effects of dexamethasone on TNF- $\alpha$ expression in the retina, as in endotoxin-induced uveitis with the use of local delivery steroid system in experimental model [1114], what has been applied in many ophthalmic diseases in children and adults $[38,40-43]$. In the mentioned processes rapid nongenomic effects on cell metabolism and cell membrane functions such as altering intracellular signal transduction pathways, limiting tissular inflammatory reactions by inhibiting migration and aggregation of macrophages with enzyme release and growth factors, fibroblastic activity suppression, reducing vascular permeability and also regulating endothelial nitric oxide synthase by non-nuclear effects are used $[9,11$ $13,29,36]$.

We are aware of some limitations of our study: (a) the relatively small sample size of the study groups which did not allow to obtain statistical differences in analysis of retina attachment; (b) there was no possibility of comparing the effects of administering different doses of Dexamethasone; (c) we did not examine the effects of severe ROP improvement by application of other steroids used by the neonatologists (hydrocortisone, bethamethasone); (d) limited follow-up duration; (e) lack of routine schemes for cortisol evaluation during the steroid application which made it difficult to supervise the task

\section{Conclusions}

The benefits of the applied therapy in premature at risk of developing threshold 3 ROP and plus disease with extraretinal fibrovascular proliferation or aggressive-posterior ROP might appear to outweigh the real or potential adverse effects of this course. Shortand long-term steroid complications should be taken into account when starting the therapy. Despite some negative opinions on systemic steroids application in early postnatal period, it appears that the risk of severe decrease of vision or blindness in low-birth weight prematures with lack of possibility for anti-angiogenic treatment, allows applying the nonstandard steroids therapy as an additional, alternative option in selected ROP [45]. Although our primary experience with Dexamethasone combined with diode laser is promising, additional large-scale prospective studies with prolonged follow-up periods should be conducted to confirm our findings.

\section{Conflict of Interest}

None of the authors has conflict of interest with the submission.

\section{Financial Support}

No financial support was received for this submission.

\section{Informed Consent}

The study was performed with informed consent and approved by the Ethics Committee.

\section{References}

1. Smolkin T, Steinberg M, Sujov P, Mezer E, Tamir A, et al. (2008) Late postnatal systemic steroids predispose to retinopathy of prematurity in very-low-birthweight infants: a comparative study. Acta Paediatr 97: 322-326.

2. Sood BG, Madan A, Saha S, Schendel D, Thorsen P, et al. (2010) Perinatal systemic inflammatory response syndrome and retinopathy of prematurity. Pediatr Res 67: 394-400.

3. Paananen R, Husa AK, Vuolteenaho R, Herva R, Kaukola T, et al. (2009) Blood cytokines during the perinatal period in very preterm infants: relationship of inflammatory response and bronchopulmonary dysplasia. J Pediatr 154: 39-43.

4. Stewart MW (2012) The expanding role of vascular endothelial growth factor inhibitors in ophthalmology. Mayo Clin Proc 87: 77-88.

5. Dammann O, Leviton A (2006) Inflammation, brain damage and visual dysfunction in preterm infants. Semin Fetal Neonatal Med 11: 363-368.

6. Kim TI, Sohn J, PI SY Yoon YH (2003) Postnatal risk factors of retinopathy of prematurity. Semin Neonatol 8:469-73.

7. Genzel-Boroviczény O, MacWilliams S, Von Poblotzki M, Zoppelli L (2006) Mortality and major morbidity in premature infants less than 31 weeks gestational age in the decade after introduction of surfactant. Acta Obstet Gynecol Scand 85: 68-73.

8. Halliday HL, Ehrenkranz RA, Doyle LW (2009) Early (<8days) postnata corticosteroids for preventing chronic lung disease in preterm infants. Arch Pediatr 17: 999-1004.

9. Rotshild T, Nandgaonkar BN, Yu K, Higgins RD (1999) Dexamethason reduces oxygen-induced retinopathy in the mouse model. Pediatr Res 46: 94-100.

10. Behar-Cohen FF, Parel JM, Pouliquen Y, Thillaye-Goldenberg B, Goureau O et al. (1997) lontophoresis of dexamethasone in the treatment of endotoxininduced-uveitis in rats. Exp Eye Res 65: 533-545.

11. Brenner T, Yamin A, Abramsky O, Gallily R (1993) Stimulation of tumor necrosis 
Citation: Modrzejewska M, Lachowicz E, Joanna Kot D, Lubiński W, Rudnicki J, et al. (2014) Early Experience with Diode Laser Combined with Systemic Steroid Therapy for Severe Stages of Retinopathy of Prematurity. J Steroids Horm Sci 5: 148. doi:10.4172/2157-7536.1000148

factor-alpha production by mycoplasmas and inhibition by dexamethasone in cultured astrocytes. rain Res 608: 273-279.

12. Yossuck P, Yan Y, Tadesse M, Higgins RD (2000) Dexamethasone and critical effect of timing on retinopathy. Invest Ophthalmol Vis Sci 41: 3095-3099.

13. Wagge A, Bakke O (1998) Glucocorticosteroids suppress the production of tumor necrosis factor by lipopolysaccharide-stimulated human monocyte. Immunology 63: 303-311.

14. Palexas GN, Sussman G, Welsh NH (1992) Ocular and systemic determination of IL-1 beta and tumour necrosis factor in a patient with ocular inflammation. Scand J Immunol Suppl 11: 173-175.

15. International Committee for the Classification of Retinopathy of Prematurity (2005) The International Classification of Retinopathy of Prematurity revisited. Arch Ophthalmol 123: 991-999.

16. Jang SY1, Choi KS, Lee SJ (2010) Delayed-onset retinal detachment after an intravitreal injection of ranibizumab for zone 1 plus retinopathy of prematurity. J AAPOS 14: 457-459.

17. Orozoco- Gómez LP, Hernández-Salazar L, Moguel-Ancheita S, et al. (2011) Laser-ranibizumab treatment for retinopathy of prematurity in umbral-preumbral disease. Three years of experience. Cir Cir 79: 225-32.

18. Andreoli CM, Miller JW (2007) Anti-vascular endothelial growth factor therapy for ocular neovascular disease. Curr Opin Ophthalmol 18: 502-508.

19. Bonsante F, Latorre G, lacobelli S, Forziati V, Laforgia N, et al. (2007) Early lowdose hydrocortisone in very preterm infants: a randomized, placebo-controlled trial. Neonatology 91: 217-221.

20. Park YJ, Kim YH, Choi WS, Chung IY, Yoo JM (2010) Treatment with triamcinolone acetonide prevents decreased retinal levels of decorin in a rat model of oxygen-induced retinopathy. Curr Eye Res 35: 657-663.

21. Goissen C, Fontaine C, Braun K, Bony H, Al-Hosri J, et al. (2011) [Prospective study at 1 week of life of thyroid function in 97 consecutive pre-term newborns under 32 weeks of gestation]. Arch Pediatr 18: 253-260.

22. Osborn DA, Hunt RW (2007) Postnatal thyroid hormones for preterm infants with transient hypothyroxinaemia. Cochrane Database Syst Rev (1): CD005945.

23. Fujitaka M, Jinno K, Sakura N, Takata K, Yamasaki T, et al. (1997) Serum concentrations of cortisone and cortisol in premature infants. Metabolism 46 518-521.

24. Ares S, Quero J, Diez J, Morreale de Escobar G (2011) Neurodevelopment of preterm infants born at 28 to 36 weeks of gestational age: the role of hypothyroxinemia and long-term outcome at 4 years. J Pediatr Endocrinol Metab 24: 897-902.

25. Field T, Hernandez-Reif M, Diego M, Figueiredo B, Schanberg S, et al. (2006) Prenatal cortisol, prematurity and low birthweight. Infant Behav Dev 29: 268275

26. Rastogi A, Akintorin SM, Bez ML, Morales P, Pildes RS (1996) A controlled trial of dexamethasone to prevent bronchopulmonary dysplasia in surfactanttreated infants. Pediatrics 98: 204-210.

27. Anttila E, Peltonemi O, Haumont D, et al. (2005) Early neonatal dexamethasone treatment for prevention of bronchopulmonary dysplasia. Randomised trial and meta-analysis evaluating the duration of dexamathsone teraphy. European Journal of Pediatrics 164: 472-481.

28. Hafezi-Moghadam A, Simoncini T, Yang E, et al. (2002) Acute cardiovascular protective effects of corticosteroids are mediated by non-transcriptional activation of endothelial nitric oxide synthase. Nat Med 8: 473-479.

29. Charles R, Neal Jr, Brian L. et al. (2003) Dexamethasone exposure during the neonatal period alters ORL1 mRNA expression in the hypothalamic paraventricular nucleus and hippocampus of the adult rat. Developmental Brain Research 146: 15-31.
30. Eriksson L, Haglund B, Ewald U, Odlind V, Kieler H (2009) Short and long-term effects of antenatal corticosteroids assessed in a cohort of 7,827 children born preterm. Acta Obstet Gynecol Scand 88: 933-938.

31. Henderson-Smart DJ, Cools F, Bhuta T, et al. (2007) Elective high frequency oscillatory ventilation versus conventional ventilation for acute pulmonary dysfunction in preterm infants. Cochrane Database Syst Rev (3): CD000104

32. Msall ME (2006) The panorama of cerebral palsy after very and extremely preterm birth: evidence and challenges. Clin Perinatol 33: 269-284.

33. Modrzejewska M, Grzesiak W, Karczewicz D, Zaborski D (2010) Refractive status and ocular axial length in preterm infants without retinopathy of prematurity with regard to birth weight and gestational age. J Perinat Med 38: 327-331.

34. Dhawan A, Dogra M, Vinekar A, et al. (2008) Structural sequelae and refractive outcome after successful laser treatment for threshold retinopathy of prematurity. J Pediatr Ophthalmol Strabismus 45: 356-361.

35. Chen YZ, Qiu J (2001) Possible genomic consequence of nongenomic action of glucocorticoids in neural cells. News Physiol Sci 16: 292-296.

36. Baud O, Foix-L'Helias L, Kaminski M, Audibert F, Jarreau PH, et al. (1999) Antenatal glucocorticoid treatment and cystic periventricular leukomalacia in very premature infants. $\mathrm{N}$ Engl J Med 341: 1190-1196.

37. Baud O, Laudenbach V, Evrard P, Gressens P (2001) Neurotoxic effects of fluorinated glucocorticoid preparations on the developing mouse brain: role of preservatives. Pediatr Res 50: 706-711.

38. Thurau SR, Frosch M, Zierhut M, Gümbel H, Heiligenhaus A (2007) [Topical and systemic corticosteroid therapy for uveitis in childhood]. Klin Monb Augenheilkd 224: 516-519.

39. Fishman JM, Burgess C, Waddell A (2011) Corticosteroids for the treatment of idiopathic acute vestibular dysfunction (vestibular neuritis). Cochrane Database Syst Rev : CD008607.

40. Bonhomme GR, Mitchell EB (2012) Treatment of pediatric optic neuritis. Curr Treat Options Neurol 14: 93-102.

41. Habot-Wilner Z, Sallam A, Roufas A, Kabasele PM, Grigg JR, et al. (2010) Periocular corticosteroid injection in the management of uveitis in children. Acta Ophthalmol 88: e299-304.

42. Figueroa MS, Noval S, Contreras I, Arruabarrena C, García-Pérez JL, et al. (2010) [Pars plana vitrectomy as anti-inflammatory therapy for intermediate uveitis in children]. Arch Soc Esp Oftalmol 85: 390-394.

43. Leder HA, Jabs DA, Galor A, Dunn JP, Thorne JE (2011) Periocula triamcinolone acetonide injections for cystoid macular edema complicating noninfectious uveitis. Am J Ophthalmol 152: 441-448.

44. Yossuck P, Yan Y, Tadesse M, Higgins RD (2001) Dexamethasone alters TNFalpha expression in retinopathy. Mol Genet Metab 72: 164-167.

45. Wallace DK, Wu KY (2013) Current and future trends in treatment of severe retinopathy of prematurity. Clin Perinatol 40: 297-310. 